\title{
A Study of the Effect of Advertising on Attracting Medical Tourism
}

\author{
Reza Azimi ${ }^{1}$, Ghahraman Mahmoudi ${ }^{*}$, Habib-Allah Esmaeili ${ }^{3}$ \\ ${ }^{1}$ Department of Health Services Management, Sari Branch, Islamic Azad University, Sari, Iran \\ ${ }^{2}$ Hospital Administration Research Center, Sari Branch, Islamic Azad University, Sari, Iran \\ ${ }^{3}$ Faculty of Health, Mashhad University of Medical Sciences, Mashhad, Iran
}

Corresponding Author: Ghahraman Mahmoudi, PhD, Associate Professor, Hospital Administration Research Center, Sari Branch, Islamic Azad University, Sari, Iran. Tel: +98- 01133176075, Email: email:alemi.mahmudi@iausari.ac.ir

Received June 18, 2017; Accepted August 15, 2017; Online Published August 30, 2017

\begin{abstract}
Introduction: It is predicted that tourism will be the most profitable industry in the world in 2020 . The current study aimed to evaluate the influence of advertising on attracting foreign medical tourists based on the marketing mix model.

Methods: In this descriptive study, participants $(n=136)$ completed a standard questionnaire containing items on demographic characteristics and advertising practices adopted by Mashhad hospitals (13 hospitals) to attract Arabic tourists (male-female) from seven nations in the period from March 2015 to August 2016. Data description was performed using charts and tables. The software used was SPSS 21.

Results: The results showed that $44.1 \%$ of medical tourists were satisfied with advertising practices. In terms of education, 85 (62.8\%) tourists did not have a high school diploma. Seventy-six subjects (55.9\%) were referred to hospitals by friends and acquaintances, $38.2 \%$ were referred by their physicians, and only $5.9 \%$ of tourists were attracted by other advertising methods.

Conclusion: According to the results, most patients did not consider advertising strategies effective, and the advertising methods seemed to be unsuccessful in attracting people with a higher education. Therefore, it is suggested that advertising practices be revised and novel methods be adopted to appeal to a greater range of potential tourists.

Keywords: Medical Tourism, Hospitals, Marketing
\end{abstract}

Citation: Azimi R, Mahmoudi G, Esmaeili HA. A study of the effect of advertising on attracting medical tourism. Int J Travel Med Glob Health. 2017;5(3):89-93. doi:10.15171/ijtmgh.2017.19.

\section{Introduction}

The medical tourism market is considered to be a revenuegenerating and competitive industry; it is also a novel field in the tourism sector. At the macro level, governments are eager to utilize the economic advantages originating from the tourism industry in future years. ${ }^{1}$ Developing countries in Asia have begun attracting medical tourists. Globalization and trade liberalization have influenced rapid growth in the field of health services. ${ }^{2}$

Medical tourists can enjoy their trip during the treatment period by choosing a destination with exotic tourist attractions. Today, the strategy of marketing campaigns that promote "medical tourism" is to combine healthcare services with other activities such as adventure, relaxation, and fun. ${ }^{3}$

Iran's crude oil export is a major source of foreign exchange earnings. Given Iran's economic dependence on oil export revenues, it is essential to reinforce foreign exchange flows by investing in other products and services. Iran has a great potential to produce and deliver specific products and services, and these capacities can be tapped through investment geared at realizing the potentials of this sector as a major source of foreign currency. Undoubtedly, medical tourism is one of these services. According to the 20 -year vision plan, Iran is expected to become the first destination of medical tourism in the region. Therefore, to turn into a center for health services in the region before the year 2025, Iran should be able to attract 20 million tourists and generate revenue of 15 billion dollars annually. ${ }^{4}$

Medical tourism in Iran, despite the high quality and affordability of healthcare, has failed to gain its proper position in the market, mainly because of the lack of proper advertising strategies; thus, this fledgling industry is still in its early stages. As stipulated in national planning, the government should be able to meet $30 \%$ of health demands

Copyright $(0) 2017$ The Author(s). This is an open-access article distributed under the terms of the Creative Commons Attribution License (http:// creativecommons.org/licenses/by/4.0), which permits unrestricted use, distribution, and reproduction in any medium, provided the original work is properly cited. 
of the country through exports of goods, health services and medical tourism by the end of the Fourth Development Plan.

However, development of the medical tourism industry in Iran may give rise to issues such as brokerage problems which will require serious attention. In addition, the media in Iran should gear the popular culture towards the reception of tourists from different countries. Furthermore, greater attention should be paid to advertising in international media to promote the attraction of tourists from many countries. ${ }^{5}$

Izadi et al claimed that today, with the advent of standards and global regulations in different parts of the world, people are looking for the highest quality treatment at a competitive cost. ${ }^{6}$ Ozan-Rafferty et al contended that information sharing largely resembles the growth of the body. Patients share their experiences via Facebook and other social networks. ${ }^{7}$ Penney et al argued that the government needs to have more control over health tourism mediators so that patients have access to more accurate information and are, therefore, in a better position to make decisions regarding their health tourism destination. ${ }^{8}$ A literature search determined that the general infrastructure and priorities of this industry have been studied, but so far, scant attention has been paid to the views of patients as direct beneficiaries of these services. In the current study, attempts have been made to incorporate the views of patients on the impact of advertising on their decision to use health services in Iran.

\section{Methods}

This is an applied study that adopted a descriptive method to explore its subject in a cross-sectional manner. The study population consisted of all foreign patients admitted to hospitals affiliated with Mashhad University of Medical Sciences. There are 47 hospitals affiliated with Mashhad University of Medical Sciences, out of which 33 are located in the city of Mashhad. Of this number, 13 hospitals, including Army 550, Aria, Imam Reza (AS), Imam Zaman (AS), Imam Hadi (AS), Shahid Kamyab, Bentolhoda, Jawad al-Aemme, Razavi, Qaem, Mehr, Mehregan, and Musa ibn Ja'far (AS), which received the majority of patients, were included in this study.

The convenience sampling method was used to select participants. To do so, eligible patients who visited hospitals during the study period and who met the study criteria were included. Given the ethnic diversity of health tourists, hospital statistics were first searched to determine the major source of health tourists. As it turned out, most patients were from neighboring Arab countries in the Persian Gulf. A standard questionnaire adapted from a research carried out at Shiraz University of Medical Sciences entitled "Developing a checklist of health marketing mix with medical tourism approach" by Rahimi Zarchi et al was selected and translated into Arabic. ${ }^{9}$

The content validity of the questionnaire was evaluated by 5 faculty members of the Medical University, and their ideas were incorporated. To check the reliability, questionnaires were given to 17 patients after a 1-day interval, and the correlation between the 2 measurements was calculated $(\mathrm{r}=0.88)$.

After assessing the questionnaire's validity and reliability and determining the sample size, the questionnaires were distributed among liaisons of hospitals affiliated with Mashhad University of Medical Sciences to be delivered to Arab tourists. Questionnaires were mainly filled out by patients during their rest time, and parents completed them for their children. Questionnaires with 10 unanswered questions or more were excluded from the study. To address any ambiguity regarding the questionnaire items, the liaisons were given special training, and the questionnaires were distributed among subjects until the quorum was met.

The collected data was then examined to check its accuracy before performing the data analysis. It should be noted that the sample size was computed based on the initial sampling, in which 17 patients completed questionnaires.

Given the huge variance in price compared to other variables, a sample size of $n=127$ was estimated in the preliminary study, with a price variance of 828 , accuracy of $95 \%$, and a 5 -unit precision. Finally, a sample of $n=136$ was considered for the study.

Data was gathered through a field study. The liaisons who distributed the questionnaires were chosen from hospital staff who were preferably familiar with the Arabic or English language.

Prior to the study, the goals of the project and questionnaires were explained to the liaisons and Persian and English copies of the questionnaire were provided to questioners so that they could address any potential ambiguity of items or answer patient questions. Completing the questionnaire took about 20 minutes provided that the patient was able to do it continuously without interruption.

Given their special conditions, patients usually completed the questionnaire in multiple stages. The project began at the beginning of March, 2015 and lasted until August, 2016. Frequency distribution tables and charts were used to describe the data. The software used was SPSS 21.

\section{Results}

In this research, 136 non-Iranian patients who were willing to respond to the questionnaire were studied. According to the results, $55.6 \%$ and $44.1 \%$ of patients, respectively, were partially or completely satisfied with the advertising strategies adopted for the promotion factor of the marketing mix model. After assigning a score of 0 to 2 to "No," "To some extent," and "Yes" options respectively, a mean and standard deviation of $1.37 \pm 0.48$ was achieved, which was close to "some extent" of satisfaction (Figure 1).

Given that the study was conducted based on Marketing Mix 7P's (Price, Place, Product, Process, Promotion, Physical evidence, People), the factor of advertising was ranked fifth after factors of staff, services, place, and process, higher than the factors of facilities and price. The study also found that the mean age of tourists was 44.8 years with a standard deviation of 17.03. On average, the length of stay of patients was 5.98 days $(\mathrm{SD}=15.8)$. The length of stay was in the range of 1 to 180 days. 


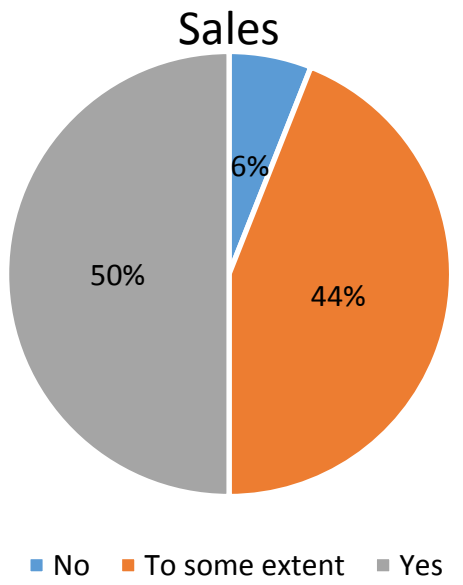

Figure 1. Frequency Distribution of Subjects Based on Satisfaction With Advertising.

The most common reason for admission was surgery (88.2\%), and among various types of surgery, cardiovascular surgery $(29.3 \%)$ was ranked first, followed by urology and general surgeries, respectively (Table 1 ). Based on the data shown in Table 2, 55.9\% of tourists were referred to medical centers by their friends and family and $38.2 \%$ were directly referred by their physicians to the hospital. Other methods of referral, including Internet searches, mediators, social networks and direct admissions, accounted for only $5.9 \%$ of tourists. Other data showed that $63.2 \%$ of patients were male and $85.3 \%$ of subjects were married.

The greatest satisfaction with advertising methods was related to promotional banners, hospital information tables, and websites. Conversely, the absence of agencies in health centers of densely populated cities, the lack of a charity plan for disadvantaged patients, and a paucity of brochures and promotional emails gained the lowest levels of satisfaction in the view of foreign medical tourists (Table 3 ).

\section{Discussion}

In today's world, advertising plays a crucial role in enhancing the efficiency of enterprises. For this reason, most firms dedicate an enormous sum of money to advertising, which is only reasonable given the nature of competition and the large number of rivals in the international market.

The results of other studies, including Turner, ${ }^{10}$ suggest that medical tourism companies make use of the internet to sell health services to prospective customers. Websites provide valuable information about companies active in medical tourism in Canada. Moreover, they offer information about destination countries and their facilities, type of health services provided, their competitive status in the national and global markets, and services related to travel arrangements in addition to promoting healthcare. ${ }^{10}$ The results of this study, however, indicated that the suggestion of medical centers by friends and acquaintances and also physicians played a major role in attracting tourists. Crooks et al argued that, contrary to the view held by most researchers and journalists according to which low treatment cost in destination countries serves
Table 1. Reasons for the Visit and Type of Surgery

\begin{tabular}{lcc}
\hline Variable & No. & Percent \\
\hline Reasons for admission & 120 & \\
Surgery & 9 & 88.2 \\
Internal disease & 7 & 6.6 \\
Diagnosis & & 5.1 \\
Type of surgery & 36 & 29.3 \\
Cardiovascular disease & 13 & 10.6 \\
Orthopedics & 16 & 13 \\
General & 19 & 15.4 \\
Urology & 15 & 12.2 \\
Ear, nose and throat & 24 & 19.6 \\
Others & & \\
\hline
\end{tabular}

Table 2. The Impact of Demographic Variables on Choice of Hospitals

\begin{tabular}{|c|c|c|c|c|c|c|}
\hline & \multicolumn{2}{|c|}{$\begin{array}{c}\text { By Friends and } \\
\text { Relatives }\end{array}$} & \multicolumn{2}{|c|}{ By Physicians } & \multicolumn{2}{|c|}{ Other Methods } \\
\hline & No. & $\%$ & No. & $\%$ & No. & $\%$ \\
\hline \multicolumn{7}{|l|}{ Age } \\
\hline$<20$ & 4 & 2.94 & 3 & 2.21 & 3 & 2.21 \\
\hline $20-39$ & 27 & 19.85 & 14 & 10.29 & 2 & 1.47 \\
\hline $40-59$ & 27 & 19.85 & 24 & 17.65 & 3 & 2.21 \\
\hline$>60$ & 18 & 13.24 & 11 & 8.09 & 0 & 0.00 \\
\hline \multicolumn{7}{|l|}{ Gender } \\
\hline Male & 44 & 32.35 & 37 & 27.21 & 5 & 3.68 \\
\hline Female & 32 & 23.53 & 15 & 11.03 & 3 & 2.21 \\
\hline \multicolumn{7}{|l|}{ Marital status } \\
\hline Single & 11 & 8.09 & 6 & 4.41 & 3 & 2.21 \\
\hline Married & 65 & 47.79 & 46 & 33.82 & 5 & 3.68 \\
\hline \multicolumn{7}{|l|}{ Education } \\
\hline Below diploma & 49 & 36.03 & 31 & 22.79 & 5 & 3.68 \\
\hline Diploma & 10 & 7.35 & 12 & 8.82 & 2 & 1.47 \\
\hline $\begin{array}{l}\text { Higher than } \\
\text { diploma }\end{array}$ & 17 & 12.50 & 9 & 6.62 & 1 & 0.74 \\
\hline \multicolumn{7}{|l|}{ Type of hospital } \\
\hline Public & 13 & 9.56 & 13 & 9.56 & 2 & 1.47 \\
\hline Private & 63 & 46.32 & 39 & 28.68 & 6 & 4.41 \\
\hline
\end{tabular}

as a major motivating factor for patients, medical tourism advertising primarily focuses on national and international prestige and the promotion of a wide range of specialized medical procedures offered to international patients. ${ }^{11}$

Emphasis on specialized treatment reflects a desire to promote the concepts of competence, professionalism, and high quality care. Moreover, images and descriptions of medical devices accompanying advertisements convey the message that the hospital is committed to providing high quality healthcare with high-tech equipment. This is consistent with the results of the present study according to which advertising is more important than price in attracting medical tourists. 
Table 3. Percentage of Responses to Items Related to Advertising

\begin{tabular}{|c|c|c|c|c|c|c|}
\hline \multirow{2}{*}{ Items } & \multicolumn{2}{|c|}{ Yes } & \multicolumn{2}{|c|}{ No } & \multicolumn{2}{|c|}{ To Some Extent } \\
\hline & No. & $\%$ & No. & $\%$ & No. & $\%$ \\
\hline This hospital sends brochures and mail to people. & 73 & 53.68 & 35 & 25.74 & 28 & 20.59 \\
\hline This hospital has an up-to-date website. & 88 & 64.71 & 18 & 13.24 & 30 & 22.06 \\
\hline This hospital uses ceremonies to introduce its capabilities. & 68 & 50.00 & 23 & 16.91 & 45 & 33.09 \\
\hline This hospital offers medical consultation through phone services. & 73 & 53.68 & 28 & 20.59 & 35 & 25.74 \\
\hline This hospital provides patient experience and feedback on the results. & 80 & 58.82 & 20 & 14.71 & 36 & 26.47 \\
\hline This hospital uses information tables in the hospital environment. & 99 & 72.79 & 13 & 9.56 & 24 & 17.65 \\
\hline This hospital uses animation for information. & 80 & 58.82 & 27 & 19.85 & 29 & 21.32 \\
\hline This hospital uses information banners. & 100 & 73.53 & 13 & 9.56 & 23 & 16.91 \\
\hline $\begin{array}{l}\text { Representative agencies of this hospital are present in the health centers and clinics } \\
\text { of crowded cities. }\end{array}$ & 60 & 44.12 & 41 & 30.15 & 35 & 25.74 \\
\hline This hospital announces its performance analysis in periodic reports to the public. & 78 & 57.35 & 24 & 17.65 & 34 & 25.00 \\
\hline This hospital uses television to advertise and inform people. & 74 & 54.41 & 26 & 19.12 & 36 & 26.47 \\
\hline This hospital offers gifts and privileges to disadvantaged people. & 63 & 46.32 & 36 & 26.47 & 37 & 27.21 \\
\hline This hospital utilizes creative techniques to inform people. & 71 & 52.21 & 24 & 17.65 & 41 & 30.15 \\
\hline
\end{tabular}

According to Donyadideh's study, the absence of advertising in target markets (outside Iran) is an obstacle to the attraction of tourists. Furthermore, negative advertising levelled against Iran by some international bodies has also contributed to the inhibition of tourism in Iran. ${ }^{12}$ According to Azadi and colleagues' findings, the promotion of medical and hospital standards can significantly improve other quality aspects of hospitals. ${ }^{13}$

The results of a study by Jabbari et al suggested that hospitals in Mashhad and Shiraz were not successful in this regard. ${ }^{14}$ The results of the current study, consistent with those mentioned above, demonstrate the inefficiency of advertising in attracting tourists. Taghvaei and Goodarzi indicated that marketing, attracting medical tourists, and reducing costs required further attention to introduce the potentials and capabilities of medical tourism in Shiraz. Taghvaei and Goodarzi highlighted that promotional campaigns, especially electronic advertising, international exhibitions, published tourist guidebooks, specialized journals and brochures, and commercials broadcast from satellite TV channels and websites are necessary measures to be taken. ${ }^{15}$

According to the current findings, the use of advertising banners, hospital information tables, and websites gained the highest satisfaction of medical tourists. Conversely, the absence of an agency in densely populated cities, the lack of charity plans for disadvantaged patients, and the lack of brochures and promotional emails gained the lowest satisfaction of foreign medical tourists. Compared to the above-named studies, some differences in terms of the content of advertisement are evident.

Taghizadeh Yazdi and Barazandeh suggested that a number of measures should be taken, such as setting up marketing offices in target markets, organizing study tours for journalists in the province, providing insurance for medical tourists, and developing a brand for the medical sector of the province. ${ }^{16}$ Abadi et al argued that the development of medical tourism can be aided by such measures as addressing issues related to medical tourism, promotion in
TV programs and local newspapers, advertising on satellite to introduce the capabilities of medical tourism with set prices and quality medical services and tourism, developing information, and marketing through the creation of tourismbased medical websites for patients to access information, especially because most medical tourists do their research and find information through internet and draft a master plan for medical tourism. ${ }^{17}$ Consistent with the results of the present study, the above-named research stressed the importance of systematic advertising and marketing for the attraction of medical tourists. Izadi et al claimed that a lack of interest and professionalism among foreign medical tourists to use international medical capacities stems from ineffective information and poor electronic public information services in hospitals. This same result was achieved by a recent study that showed "information tables in the hospital environment" are not efficient. ${ }^{18}$

\section{Conclusion}

There is a consensus among researchers that advertising plays a major role in attracting customers. Today, given the massive amount of data exchanged in communities, it is becoming increasingly difficult for customers to make decisions as they are often exposed to overwhelming data. Given that factors such as staff, services, processes, and place are the main marketing parameters affecting the tendency of patients to refer to a specific hospital, senior executives of hospitals are recommended to account for the safety, comfort, and well-being of patients as basic requirements of marketing. In addition, raising patient awareness of services and efforts to provide such services beyond mere advertising by their providers creates an opportunity to expand mutual communication with patients, which in turn can help alter the view of most patients.

\section{Limitations}

This study had a number of limitations, including poor cooperation by some hospitals and a lack of awareness 
among hospital staff about marketing strategies as well as the unwillingness of some patients to participate in the study and the unfamiliarity of staff members with the Arabic language.

\section{Authors' Contributions}

All authors significantly contributed towards this study.

\section{Conflict of Interest Disclosures}

The results of this study are not in conflict with the interests of any hospital, and the findings were purely derived from the analysis of data collected by the questionnaire.

\section{Ethical Approval}

Approval was obtained from the Ethical Committee before the study was begun (IR.MUMS.REC.1394.571).

\section{Funding/Support}

None.

\section{Acknowledgments}

This article was extracted from a master thesis entitled "Factors affecting the absorption of foreign health tourists in selected hospitals affiliated with Mashhad University of Medical Sciences based on the model of marketing mix." It was supported by the Deputy of Mashhad University of Medical Sciences in Islamic Azad University, Sari Branch, in 2015-2016.

\section{References}

1. Tabibi SJ, Nasiripour AA, Ayubian A, Bagherian MH. The relation between information mechanisms and medical tourist attraction in hospitals of Tehran, Iran. Health Information Management. 2012; 9(3):416-423. [Persian].

2. Ayoubian A, Tourani S, Hashemi Dehaghi Z. Medical tourism attraction of tehran hospitals. Int J Travel Med Glob Health. 2013;1(3):95-98

3. Dehdashti Shahrokh Z, Nakhaei H. An Entropy (Shannon) Based Approach for Determining Importance Weights of Influencing Factors in Selecting Medical Tourism Destinations. Int J Travel Med Glob Health. 2016;4(4):115-121. doi:10.21859/ijtmgh-040406.

4. Hosseini SM, Maher A, Safarian O, et al. Development Strategy of Health Tourism in Iran. Int J Travel Med Glob Health. 2015;3(4):153-158. doi:10.20286/ijtmgh-0304143.

5. Mousavi SM, Haghi M, Gharasi Manshadi M. Health tourism in Iran: a path towards sustainable development. Iran J Public Health. 2016;45(2):274-275

6. Izadi M, Ayoobian A, Nasiri T, Joneidi N, Fazel M, Hosseinpourfard MJ. Situation of health tourism in Iran opportunity or threat. J Mil Med. 2012;14(2):69-75.

7. Ozan-Rafferty ME, Johnson JA, Shah GH, Kursun A. In the words of the medical tourist: an analysis of Internet narratives by health travelers to Turkey. J Med Internet Res. 2014;16(2):e43. doi:10.2196/jmir.2694.

8. Penney K, Snyder J, Crooks VA, Johnston R. Risk communication and informed consent in the medical tourism industry: a thematic content analysis of Canadian broker websites. BMC Med Ethics. 2011;12:17. doi:10.1186/1472-6939-12-17.

9. Rahimi Zarchi M, Jabbari A, Rahimi SH, Shafaghat T, Abbasi S. Preparation and designing a checklist for health care marketing mix, with medical tourism approach. Int J Travel Med Glob Health.
Research Highlights

\section{What Is Already Known?}

The results of this study indicated that the majority of medical tourists to Iran had low levels of education. Therefore, they were more likely to be influenced by the suggestions of friends and family or trusted physicians. In addition, private hospitals were found to be significantly more successful than public hospitals in attracting tourists. Most patients were in the age group of 20 to 60 years. In the literature review, no data on the age groups of patients was found, so a comparison with the present study was not possible.

\section{What This Study Adds?}

The results of this study suggested that the main reasons for the tendency of foreign patients to refer to hospitals in Mashhad were associated with factors such as provision of quality service and professional staff and physicians rather than factors such as price and advertising. Therefore, it is necessary to adopt appropriate and efficient advertising strategies to introduce products with an eye towards the needs of target communities. In this context, the use of modern advertising methods that engage various social groups is of paramount importance.

2013;1(4):103-108.

10. Turner L. Canadian medical tourism companies that have exited the marketplace: Content analysis of websites used to market transnational medical travel. Global Health. 2011;7:40. doi:10.1186/1744-8603-7-40.

11. Crooks VA, Turner L, Snyder J, Johnston R, Kingsbury P. Promoting medical tourism to India: messages, images, and the marketing of international patient travel. Soc Sci Med. 2011;72(5):726-732. doi:10.1016/j.socscimed.2010.12.022.

12. Donyadideh A. The obstacles impeding the development of Irans tourism industry with emphasis on marketing. J Hosp Manage Tourism. 2013;4(3):59-68. doi:10.5897/JHMT10.007.

13. Azadi F, Maleki M, Tabibi SJ, Azmal M. A medical tourist perception of iranian hospital quality: limited employee foreign language skills negatively impact communication. Int J Hosp Res. 2012;1(2):85-90.

14. Jabbari A, Rahimi Zarchi MK, Kavosi Z, Shafaghat T, Keshtkaran A. The marketing mix and development of medical tourism in shiraz. Mater Sociomed. 2013;25(1):32-36. doi:10.5455/ msm.2013.25.32-36.

15. Taghvaei $M$, Goodarzi $M$. Developing and prioritizing the formation of strategies in medical tourism (case study: Shiraz metropolis). Research and Urban Planning. 2016;7(2):1-22.

16. Taghizadeh Yazdi MR, Barazandeh $H$. Identifying and ranking health tourism development barriers in Iran using fuzzy VIKOR method. Asian Soc Sci. 2016;12(5):54. doi:10.5539/ass.v12n5p54.

17. Abadi FA, Sahebi I, Arab A, Alavi A, Karachi H. Application of best-worst method in evaluation of medical tourism development strategy. Decision Science Letters. 2018;7(1):77-86. doi:10.5267/j. dsl.2017.4.002

18. Izadi M, SaadatSH, Ayoubian A, Hashemi Dehaghi Z, Karbasi MR, Jalali AR. Health tourism in Iran; identifying obstacles for development of this industry. Int J Travel Med Glob Health. 2013;1(3):89-94. 